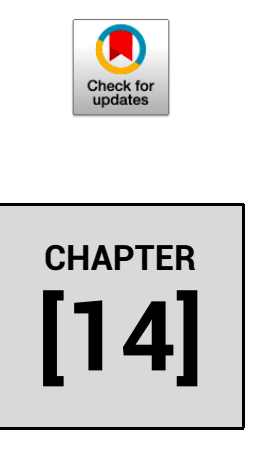

In: Environmental Degradation: Causes and Remediation Strategies

DOI: 10.26832/aesa-2020-edcrs-014

\title{
Strategies to prevent environmental stresses by silicon fertilization in rice crop
}

\author{
Ardeep Kumar \\ Department of Agronomy, College of Agriculture, \\ G.B. Pant University of Agriculture and Technology, Pantnagar - 263153 (Uttarakhand), India
} Rice is the most important staple food crop for a large part of the world's population, especially in East and South Asia, Middle East, Latin America, and the West Indies. As the population increases rapidly in these regions, the demand for rice will grow to an estimated 2000 million metric tons by 2030 . To supply to this increasing demand, the methods of rice production will require significant improvement. Achieving this goal, however, is sure to be a challenge with respect to future climatic changes, which will basically be characterized by current global warming trends. The rise in temperatures and levels of carbon dioxide and uncertain rainfall associated with climate change may have serious adverse effects either directly or indirectly on the growth, development, and yield of rice crops. To cope with the unfavorable growth conditions, plants respond with a series of morphological, biochemical, and molecular adaptations, aiming at safeguarding the basic metabolic activities. All the unfavorable factor which limit crop yield may be consider as a stress. Silicon seems to protect plants from such types of stresses caused by environmental degradation. This can be managed by proper agronomic practices or developing resistance variety. Therefore, in this chapter we showed that how we can manage these stresses to boost rice productivity in changing climatic scenario while using silicon fertilizer as a protective agent.

\section{KEYWORDS}

Climate change, Environmental stress, Global warming, Rice crop, Productivity

D. Ardeep Kumar, Email: ardeepkumar4@gmail.com 


\section{Introduction}

Stress is an external factor that decreases crop yields from yield maximum to a lower level for examples diseases, insects, salinity, and excesses of trace elements. Due to global warming, and potential climate abnormalities associated with it, crops typically encounter an increased number of abiotic and biotic stress combinations, which severely affect their growth and yield (Ramegowda and Kumar, 2015; Kumar et al., 2020). Concurrent occurrence of abiotic stresses such as drought and heat has been shown to be more destructive to crop production than these stresses occurring separately at different crop growth stages (Prasad et al., 2011). Abiotic stress conditions such as drought, high and low temperature and salinity are known to influence the occurrence and spread of pathogens, insects, and weeds (Peters et al., 2014). They can also result in minor pests to become potential threats in future. These stress conditions also directly affect plant-pest interactions by altering plant physiology and defense responses. Additionally, abiotic stress conditions such as drought enhance competitive interactions of weeds on crops as several weeds exhibit enhanced water use efficiency than crops (Valerio et al., 2013). Abiotic stresses like salinity, water deficit, chilling, and heavy metals adversely affect the growth and several physiological processes of plants. In general, low temperature mainly results in mechanical constraint, whereas salinity and drought exert their malicious effect by disrupting the ionic and osmotic equilibrium of the cell. The detrimental effects of excess salts are the consequences of water deficit that results from decreased osmotic/water potential of soil solution due to high solute concentration in the soil, as well as ion-specific stresses due to altered $\mathrm{Na}^{+} / \mathrm{K}^{+}$ratios and $\mathrm{Na}^{+} / \mathrm{Cl}^{-}$ratios that are inimical to the plants. The phytohormone abscisic acid (ABA) regulates desiccation tolerance in seeds as well as in vegetative tissue. The endogenous ABA concentration increases in different plant tissues during drought, salinity, or cold induced oxidative stress. To cope with the unfavorable growth conditions, plants respond with a series of morphological, biochemical, and molecular adaptations, aiming at safeguarding the basic metabolic activities. It is now well known that the stress signal is first perceived at the membrane level by the receptors and then transduced into the cell to switch on the stress responsive genes for mediating stress tolerance. Population growth and water scarcity combined mean that there is no alternative but induced by drought, high salinity, and low temperature stresses, and their products are thought to function in stress tolerance and response (Roychoudhury et al., 2013).

\section{Environmental factors responsible stress in rice crop}

\section{Droughts}

Drought is generally avoided in areas where irrigation water is available throughout the season, 
but it is a consistent feature across much of the 63.5 million hectares of rainfed rice sown annually, most of which is in tropical Asia, Africa and Latin America. It can occur at any stage during the rice cropping season, but it is more devastating when it occurs just prior to flowering than it is during the vegetative stage, with substantial effects on grain yield. About $70 \%$ of the rice area in sub- Saharan Africa is rainfed. The spatial and temporal variability of rainfall in this region expose rice plants to frequent drought spells. Regardless of the total rainfall and distribution, the poor physical properties of highly weathered, coarse-textured soils in some parts of sub-Saharan Africa induce low water-holding capacity and establish water deficit as a major constraint to rainfed crop yields in sub-Saharan Africa. This is particularly true for upland rice, which makes up $32 \%$ of rice-growing areas in sub-Saharan Africa. Analysis of farmer perceptions in 18 countries in sub-Saharan Africa across rice environments provided evidence that in 2008 an estimated $10 \%$ of rice farmers experienced drought affecting $37 \%$ of their rice area, causing $29 \%$ of rice yield loss. The diversity of affected production systems, variability of drought in terms of timing and severity, and the multiple traits involved in drought tolerance require strategic research to prioritize and define environment-specific approaches for developing drought-tolerant rice cultivars.

\section{Submergence and water logging}

Rice plants require water for growth but excess water that occurs during submergence or water logging is harmful or even lethal. A submerged plant is defined as "a plant standing in water with at least part of the terminal above the water or completely covered with water" (Catling, 1992). Submergence subjects plants to the stresses of low light, limited gas diffusion, effusion of soil nutrients, mechanical damage, and increased susceptibility to pests and diseases (Ram et al., 1999). Basically, flooding (i.e., submergence) can be classified into "flash flooding" and "deepwater flooding" in accordance with the duration of flooding and the water depth. Flash flooding, which generally lasts less than a few weeks, is caused by heavy rain but the depth is not very deep. On the other hand, deepwater flooding, which lasts for several months, occurs during the rainy season, and the water depth reaches several meters (Hattori et al., 2011). Water logging is defined as a condition of the soil in which excess water limits gas diffusion (Setter and Waters, 2003). Oxygen diffusivity in water is approximately 10,000 times slower than in air, and the flux of $\mathrm{O}_{2}$ into soils is approximately 320,000 times less when the soil pores are filled with water than when they are filled with gas (Colmer and Flowers, 2008). The principal cause of damage to plants grown in waterlogged soil is inadequate supply of oxygen to the submerged tissues as a result of slow diffusion of gases in water and rapid consumption of $\mathrm{O}_{2}$ by soil microorganisms. Oxygen deficiency in waterlogged soil occurs within a few hours under some conditions. In addition to the $\mathrm{O}_{2}$ deficiency, production of toxic substances such as $\mathrm{Fe}^{2+}, \mathrm{Mn}^{2+}$, and $\mathrm{H}_{2} \mathrm{~S}$ by 
reduction of redox potential causes severe damage to plants under waterlogged conditions (Setter et al. 2009).

\section{Soil salinity}

Irrigation has the potential to ensure high rice yields and is a good strategy to offset recurrent droughts. Unfortunately, soils of most irrigated areas have continued to be degraded as a result of poor irrigation practices and the absence of efficient drainage. These have led to a rapid rise in the water table and an increase in soil sodium/alkalinity and salinity (Bertrand et al., 1993). In the Office du Niger (Mali), $50 \%$ of the water table is now saline and occasionally very saline despite low mineral content of the irrigation water (Bertrand et al., 1993). In the Senegal River delta, marine-derived soil salinity is an inherent problem and sodicity is increasing in irrigated flood plains in inland areas due to high evaporation, rising groundwater tables and poor drainage (Matlon et al., 1998). Miézan and Dingkuhn (2001) observed that waters of the Niger and Senegal rivers carry substantial alkalinity, and the salt content of water sometimes increases markedly between the main rivers and the actual irrigation site. However, van Asten et al. (2003) show that salt accumulation in the soils of Sahelian countries has more to do with the underlying bedrock than with the irrigation system. Examining soils in the irrigated areas of Foum Gleita (Mauritania) they found that the geographical distribution of salt was not related to the presence of irrigation or drainage canals. Also the alkaline salts present in the upper soil layers in Foum Gleita did not come from irrigation water, but from the underlying bedrock. Additional to the salt stress itself, the high $\mathrm{pH}$ resulting from the sodification/ alkalinization reduces the availability of plant nutrients such as zinc and increases nitrogen losses through volatilization (Miézan and Dingkuhn, 2001). However, salinity tolerance at these two stages is only weakly associated (Moradi et al., 2003). Discovering and combining suitable tolerance traits for both stages is essential for developing resilient salt-tolerant varieties. Moreover, the salt-tolerance level of cultivars depends on environmental conditions (Asch et al., 1997). Generally, salinity effects on rice are more severe in arid climates than in humid ones. For example, salinity levels at an electric conductivity (EC) of $9.5 \mathrm{mS} / \mathrm{cm}$ were reported to cause a $50 \%$ yield loss in the humid tropics (Flowers and Yeo, 1981), whereas under the arid conditions of the Sahelian dry season an equivalent yield loss was observed at an EC of only $3.5 \mathrm{mS} / \mathrm{cm}$ (Dingkuhn et al., 1993).

\section{Role of silicon in enhancing the resistance to environmental stresses}

\section{Silicon and rice blast disease}

The suppressive effect of Si on rice blast was reported as early as 1917 by Onodera (1917). Rice blast, caused by Magnaporthe grisea, is the most destructive fungal disease of rice, particularly in 
temperate, irrigated rice and tropical upland rice. The pathogen can infect all the above-ground parts of the rice plant, but occurs most commonly on leaves causing leaf blast during the vegetative stage of growth or on neck nodes and panicle branches during the reproductive stage, causing neck blast (Bonman et al., 1989). Silicon reduces the epidemics of both leaf and panicle blast at different growth stages. In Florida, where soil is deficient in $\mathrm{Si}$, application of silicate fertilizer is as effective as fungicide application in controlling rice blast (Datnoff et al., 1997). Rice seedling blast is significantly suppressed by the application of Si fertilizers in the nursery (Maekawa et al., 2001).

\section{Silicon and powdery mildew disease}

Silicon has been reported to prevent the incidence of powdery mildew disease, which is caused by Sphaerotheca juliginea, in a number of plant species. Miyake and Takahashi (1983) reported that by increasing the Si concentration in the culture solution, the Si content in the cucumber shoot increased, resulting in a reduced incidence of powdery mildew disease. In strawberry, when the Si content of leaves increased proportionally to the increase of the Si concentration in the culture solution, the incidence of powdery mildew decreased (Kanto, 2002). Silicon deficiency in barley and wheat leads to a poor growth habit and increased powdery mildew susceptibility (Zeyen, 2002). Menzies et al. (1991) found that infection efficiency, colony size, and germination of conidia were reduced when cucumbers were grown in nutrient solutions with high concentrations of Si. Foliar application of $\mathrm{Si}$ has been reported to be effective in inhibiting powdery mildew development on cucumber, muskmelon, and grape leaves (Bowen et al., 1992). Si applied to leaves may deposit on the surface of leaves and playa similar role to that of Si taken up from the roots.

\section{Silicon and other diseases}

In addition to blast and powdery mildew, the occurrence of brown spot, stem rot, sheath brown rot on rice, fusarium wilt, and corynespora leaf spot on cucumber decreased by increasing the $\mathrm{Si}$ supply. In turfgrass, several diseases were also suppressed by Si application (Datnoff et al., 2002). Rice bacterial blight caused by Xanthomonas oryzae pv. oryzae ( $\mathrm{Xoo}_{\mathrm{o}}$ is a serious disease worldwide. Chang et al. (2002) reported that in the cultivar TNI which is susceptible to this disease the Si content in leaves was lower than that of the resistant breeding line, TSWY7 under the nutrient cultural system adopted. The degree of resistance to this disease increased in parallel with the increased amount of applied silicon. Si-induced decrease of soluble sugar content in the leaves seems to contribute to the field resistance of the disease. Silicon is also effective in increasing the resistance to the fungal diseases caused by Pythium ultimum and Paphani dermatum in cucumber roots (Cherif et al., 1994). 


\section{Silicon and pests}

Silicon suppresses insect pests such as stem borer, brown plant hopper, rice green leaf hopper, and white backed plant hopper, and non insect pests such as leaf spider and mites (Savant et al., 1997). Stems attacked by the rice stem borer were found to contain a lower amount of Si (Sasamoto, 1961). In a field study, a positive relationship between the Si content of rice and resistance to the brown plan thopper has been observed (Sujatha et al., 1987).

\section{Possible mechanisms involved}

Two hypotheses for the Si-enhanced resistance to diseases and pests have been proposed. One is that $\mathrm{Si}$ deposited on the tissue surface acts as a physical barrier. It prevents physical penetration and / or makes the plant cells less susceptible to enzymatic degradation by fungal pathogens. This mechanism is supported by the positive correlation between the Si content and the degree of suppression of diseases and pests. The other one is that $\mathrm{Si}$ functions as a signal to induce the production of phytoalexin (Cherif et al., 1994). Si application to cucumber resulted in the stimulation of the chitinase activity and rapid activation of peroxidases and polyphenol oxidases after infection with Pythium spp. Glycosidically bound phenolics extracted from Si-treated plants when subjected to acid or B-glucosidase hydrolysis displayed a strong fungistatic activity. However, in oat attacked by Blumeria graminis, Si deficiency promoted the synthesis of phenolic compounds (Carver et al., 1998).

The phenylalanine ammonia-lyase activity was enhanced by $\mathrm{Si}$ deficiency. The reason why $\mathrm{Si}$ deficiency exerts opposite effects on the synthesis of phenolic compounds, as a disease response in different plant species, has not been elucidated. Recently, Kauss et al. (2003) have reported that during the induction of systemic all acquired resistance (SAR) in cucumber, the expression of a gene encoding a novel proline-rich protein was enhanced. This protein has C-terminal repetitive sequences containing an unusually high amount of lysine and arginine. The synthetic peptide derived from the repetitive sequences was able to polymerize orthosilicic acid to insoluble silica, which is known to be involved in cell wall reinforcement, at the site of the attempted penetration of fungi into epidermal cells.

\section{Silicon and radiation damage}

Silicon seems to protect plants from radiation injury. When rice seedlings (30-days old) were irradiated with different doses of $y$-rays, the decrease in the dry weight was less appreciable in the Si-supplied plants than in the Si plants that had not been treated with Si, suggesting that $\mathrm{Si}$ increases the resistance of rice to radiation stress (Takahashi, 1966). Furthermore, when the plant was supplied with $\mathrm{Si}$ after radiation treatment, the growth recovery was faster compared to that of the plants without Si supply. 


\section{Silicon and water stress}

Water deficiency (drought stress) leads to the closure of stomata and subsequent decrease in the photosynthetic rate. Silicon can alleviate water stress by decreasing transpiration. Transpiration from the leaves occurs mainly through the stomata and partly through the cuticle. As $\mathrm{Si}$ is deposited beneath the cuticle of the leaves forming a Si-cuticle double layer, the transpiration through the cuticle may decrease by Si deposition. Silicon can reduce the transpiration rate by $30 \%$ in rice, which has a thin cuticle (Ma et al., 2001). Under water-stressed conditions (low humidity), the effect of $\mathrm{Si}$ on rice growth was more pronounced than on rice that cultivated under non-stressed conditions (high humidity) (Ma et al., 2001). When rice leaves were exposed to a solution containing polyethylene glycol (PEG), electrolyte leakage (EL) (an indicator of membrane lesion) from the leaf tissues decreased with the increase in the level of $\mathrm{Si}$ in the leaves (Agarie et al., 1998). The level of polysaccharides in the cell wall was higher in the leaves containing $\mathrm{Si}$ than in those lacking $\mathrm{Si}$. These results suggest that $\mathrm{Si}$ in rice leaves is involved in the water relations of cells, such as mechanical properties and water permeability. Among the yield components, the percentage of ripened grains is most affected by Si in both rice and barley (Ma and Takahashi, 2002). This function of Si may be attributed to the alleviative effect of Si on water stress. One important factor for the normal development of the spikelets is to keep a high moisture condition within the hull (Seo and Ohta, 1982). The Si content in the hull of the rice grain becomes as high as $7 \% \mathrm{Si}$ and that of the barley grain is $1.5 \%$. Silicon in the hull is also deposited between the epidermal cell wall and the cuticle, forming a cuticle-Si double layer as in the leaf blades. However, in contrast to the leaves, transpiration occurs only through the cuticle because the hull does not have a stoma. Silicon is effective in decreasing the transpiration from the hull. The rate of water loss from Si free spikelet's was about $20 \%$ higher than that from spikelet's containing Si (7\% Si) at both the milky and maturity stages (Ma et al., 2001). Therefore, Si plays an important role in keeping a high moisture condition within the hull by decreasing the transpiration rate from the hull. This is especially important under water deficiency stress and stress associated with climatic conditions.

\section{Silicon and stress associated with climatic conditions}

Silicon application in rice is effective in alleviating the damage caused by climatic stress such as typhoons, low temperature and insufficient sunshine during the summer season (Ma and Takahashi, 2000). A typhoon attack usually causes lodging and sterility in rice, resulting in a considerable reduction of the rice yield. Deposition of $\mathrm{Si}$ in rice enhances the strength of the stem by increasing the thickness of the culm wall and the size of the vascular bundles (Shimoyama, 1958), thereby preventing lodging. Strong winds also cause excess water loss from the spikelets, resulting in sterility. Silicon deposited on the hull is effective in preventing excess water loss. 
In addition, the effect of $\mathrm{Si}$ on the rice yield is also obvious under stress due to low temperatures and insufficient sunshine (Ma and Takahashi, 2002).

\section{Silicon and heat stress}

Silicon also increases the tolerance to heat stress in rice plants. Agarie et al. (1998) observed that electrolyte leakage caused by high temperature $\left(42^{\circ} \mathrm{C}\right)$ was less pronounced in the leaves grown with $\mathrm{Si}$ than in those grown without $\mathrm{Si}$. These results suggest that $\mathrm{Si}$ may be involved in the thermal stability of lipids in cell membranes although the mechanism has not been elucidated.

\section{Conclusion}

Si enhanced resistance to diseases and pests. Si deposited on the tissue surface acts as a physical barrier. It prevents physical penetration and / or makes the plant cells less susceptible to enzymatic degradation by fungal pathogens. It provides strength to the stem by increasing the thickness of the culm wall and the size of the vascular bundles. Si is deposited beneath the cuticle of the leaves forming a Si-cuticle double layer which act as barrier for insect and pest attack it also reduces the transpiration losses. Thus it can be concluded that Si has the capacity to provide resistance against environmental stress for the better growth and development of rice plant.

\section{References}

Agarie, S., Hanaoka, N., Ueno, O., Miyazaki, A., Kubota, F., Agata, W. and Kaufman, P.B. (1998). Effect of silicon on tolerance to water deficit and heat stress in rice plants (Oryza sativa L.), monitored by electrolyte leakage. Plant Production Science, 1: $96-103$

Asch, F., Dingkuhn, M. and Dorffling, K. (1997). Physiological stresses of irrigated rice caused by soil salinity in the Sahel. In: Miezan, K.M., Wopereis, M.C.S., Dingkuhn, M., Deckers, J. and Randolph, T.F. (eds) Irrigated Rice in the Sahel: Prospects for sustainable development. West Africa Rice Development Association, Bouaké, Côte d'Ivoire, pp. 247-273.

Asten, P.J.A., Barbiéro, L., Wopereis, M.C.S., Maeght, J.L. and Zee, S.E.A.T.M. (2003). Actual and potential salt-related soil degradation in an irrigated rice scheme in the Sahelian zone of Mauritania. Agricultural Water Management, 60(1): 13-32.

Bertrand, R., Keita, B. and N'Diaye, M.K. (1993). Soil degradation in the irrigated areas of the major valleys of the southern Sahara (Case of the Niger Office in Mali). Cahier Agricultures, 2: 318-329.

Bonman, J.M., Estrada, B.A. and Bandong, J.A. (1989). Leaf and neck blast resistance in tropical lowland rice cultivars. Plant Disease. 73: 388-390

Bowen, P., Menzies, J. and Ehret, D. (1992). Soluble silicon sprays inhibit powdery mildew development on grape leaves. Journal of the American Society for Horticultural Science, 117: 906-912

Carver, T.L.W., Robbins, M.P., Thomas, B.J., Troth, K., Raistrick, N. and Zeyen, R.J. (1998). Silicon deprivation enhances localized auto fluorescent responses and phenylalanine ammonia-lyase activity in oat attacked by Blumeria graminis. Physiological and Molecular Plant Pathology, 52: 245-257

Catling, D. (1992). Rice in deep water. London: MacMillan Press

Chang, S.J., Tzeng, D.D. and Li, C.C. (2002). Effect of silicon nutrient on bacterial blight resistance of rice (Oryza sativa L.). 
Abstract of Second Silicon in Agriculture Conference, pp. 31- 33

Cherif, M., Asselin, A. and Belanger, R.R. (1994). Defense responses induced by soluble silicon in cucumber roots infected by Pythium spp. Phytopathology, 84: 236-242

Colmer, T.D. and Flowers, T.J. (2008). Flooding tolerance in halophytes. New Phytologist, 179: 964-974

Datnoff, L.E., Brecht, M.O., Kucharek, T.A. and Nagata, R.T. (2002). The role of silicon in turfgrass disease management. Abstract of Second Silicon in Agriculture Conference, pp. 105-110

Datnoff, L.E., Deren, C.W. and Snyder, G.H. (1997). Silicon feltilization for disease management of rice in Florida. Crop Protection, 16: 525-531

Dingkuhn, M., Asch, F. and Miezan, K. (1993). Salt tolerance of rice varieties under irrigated conditions in the Sahel. In: WARDA Annual Report 1992. West Africa Rice Development Association, Bouaké, Côted'Ivoire.

Flowers, T. and Yeo, A. (1981). Variability in the resistance of sodium chloride salinity within rice (Oryza sativa L.) varieties. New Phytologist, 88: 363-373.

Hattori, Y., Nagai, K., Furukawa, S., Song, X.J., Kawano, R., Sakakibara, H., Wu, J., Matsuoka, T., Yoshimura, A., Kitano, H., Matsuoka, M., Mori, H. and Ashikari, M. (2009). The ethylene response factors SNORKEL1 and SNORKEL2 allow rice to adapt to deep water. Nature, 460: 1026-1030

Kauss, H., Seehaus, K., Franke, R., Gilbert, S., Dietrich, R.A. and Kroger, N. (2003). Silica deposition by a strongly cationic proline- rich protein from systemically resistant cucumber plants. Plant, 1(33): 87-95

Kumar, V., Kumar, P. and Khan, A. (2020). Optimization of PGPR and silicon fertilization using response surface methodology for enhanced growth, yield and biochemical parameters of French bean (Phaseolus vulgaris L.) under saline stress. Biocatalysis and Agricultural Biotechnology, 23: 101463, https://doi.org/10.1016/j.bcab.2019.101463

Ma, J.F. and Takahashi, E. (2000). Soil, Fertilizer, and Plant Silicon Research in Japan, Elsevier Science, Amsterdam

Ma, J.F. and Takahashi, E. (2002). Effect of silicon on the growth and phosphorus uptake of rice. Plant and Soil, 126: 115-119

Ma, J.F., Tamai, K., Ichii, M. and Wu, K. (2001). A rice mutant defective in active Si uptake. Plant Physiology, 130: $2111-2117$

Maekawa, K., Watanabe, K., Aino, M. and Iwamoto, Y. (2001). Suppression of rice seedling blast with some silicic acid materials in nursery box. Journal of Soil Science and Plant Nutrition, 72: 56- 62

Matlon, P., Randolph, T. and Guei, R. (1998). Impact of rice research in West Africa. In: Impact of Rice Research. Proceedings of the International Conference on the Impact of Rice Research, Bangkok, Thailand, 3-5 Jun 1996. Thailand Development Research Institute, Bangkok, Thailand and International Rice Research Institute, Manila, Philippines, pp. 383-404.

Menzies, J.G., Ehret, D.L., Glass, A.D.M., Helmer, T., Koch, C. and Seyward, F. (1991). Effects of soluble silicon on the parasitic fitness of Sphaerotheca juliginea on Cucumis sativus. Phytopathology, 81: 84-88

Miézan, K. and Dingkuhn, M. (1994). Rice and salinity in the Sahel. Ag-Sieve, 6(6): 4

Miyake, Y. and Takahashi, E. (1983). Effect of silicon on the growth of solution-cultured cucumber plant. Journal of Soil Science and Plant Nutrition, 29: 71-83

Moradi, F., Ismail, A., Gregorio, G. and Egdane, J. (2003). Salinity tolerance of rice during reproductive development and association with tolerance at the seedling stage. Indian Journal of Plant Physiology, 8: 105-116.

Onodera, I. (1917). Chemical studies on rice blast. Sci. Agric. Soc., 180:606-617

Peters, K., Breitsameter, L. and Gerowitt, B. (2014). Impact of climate change on weeds in agriculture: a review. Agricultural Biotechnology and Sustainable Development, 34: 707-721.

Prasad, P.V.V., Pisipati, S.R., Momcilovic, I. and Ristic, Z. (2011). Independent and combined effects of high temperature and drought stress during grain filling on plant yield and chloroplast EF-Tu expression in spring wheat. Journal of Agronomy and Crop Science, 197: 430-441.

Ram, P.C., Singh, A.K., Singh, B.B., Singh, V.K., Singh, H.P., Setter, T.L., Singh, V.P., Singh, R.K. (1999). Environmental characterization of floodwater in eastern India: relevance to submergence tolerance of lowland rice. Experimental Agriculture, 35: 141-152

Ramegowda, V. and Kumar, M.S. (2015). The interactive effects of simultaneous biotic and abiotic stresses on plants: mechanistic understanding from drought and pathogen combination. Journal of Plant Physiology, 176: 47-54. 
Roychoudhury, A., Paul, S. and Basu, S. (2013). Cross-talk between abscisic acid-dependent and abscisic acid-independent pathways during abiotic stress. Plant Cell Reports, 32(7): 985-1006

Sasamoto, K. (1961). Resistance of the rice plant applied with silicate and nitrogen fertilizers to the rice stem borer Chilo suppressalis WALKER. Proc. Fac. Liberal Arts Education, Yamanashi University, pp. 3: 1-73

Savant, N.K., Snyder, G.H. and Datnoff, L.E. (1997). Silicon management and sustainable rice production. Adjacent Agronomy, 58: 151-199

Seo, S.W. and Ohta, Y. (1982). Role of the hull in the ripening of rice plant. Water loss in hull and development of rice kernel. Japanese Journal of Crop Science, 51: 529-534

Setter, T.L. and Waters, I. (2003). Review of prospects for germplasm improvement for water logging tolerance in wheat, barley and oats. Plant and Soil, 253:1-34

Setter, T.L., Waters, I., Sharma, S.K., Singh et al. (2009). Review of wheat improvement for waterlogging tolerance in Australia and India: the importance of anaerobiosis and element toxicities associated with different soils. Annals of Botany, 103: 221 $-235$

Sujatha, G., Reddy, G.P.V. and Murthy, M.M.K. (1987). Effect of certain biochemical factors on expression of resistance of rice varieties to brown planthopper (Nilaparvata lugens Stal). Research Journal of Andhra Pradesh Agricultural University, 15: 124 $-128$

Takahashi, E. (1966). Effect of silicon on resistance of rice to radiation. Japanese Journal of Crop Science, 37:183-188

Valerio, M., Lovelli, S., Perniola, M., Di Tommaso, T. and Ziska, L. (2013). The role of water availability on weed-crop interactions in processing tomato for southern Italy. Acta Agriculturae Scandinavica, 63: 62-68

Zeyen, R.J. (2002). Silicon in plant cell defenses against cereal powdery mildew disease. Abstract of Second Silicon in Agriculture Conference, pp. 15-21

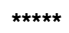

Cite this chapter as: Kumar, A. (2020). Strategies to prevent environmental stresses by silicon fertilization in rice crop. In: Environmental Degradation: Causes and Remediation Strategies, Volume 1, Eds. Kumar, V., Singh, J. and Kumar, P., pp. 205214, https://doi.org/10.26832/aesa-2020-edcrs-014 